
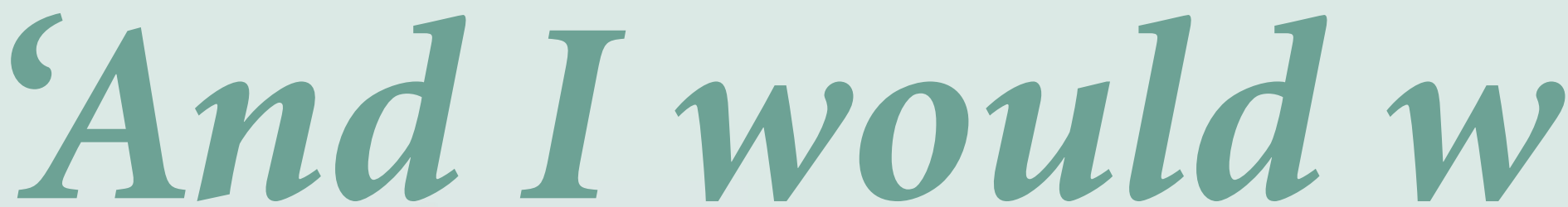

\title{
^ AMARILLO
}

\section{^ TIMBUKTU}

\section{$\star$ PETERSFIELD}

\section{BRIGHTON}

The determination of CDTs in the UK knows no bounds. CDT Paul Ahern rolled team-building and fundraising into one by taking part in the Trailwalker 2007.

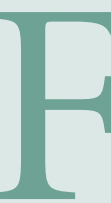

riday 13 July: unlucky for some, but for me and many other clinical dental technicians (CDTs), it was a day to go down in history. It was the day that I went to the Royal College of Surgeons to receive my Diploma in Clinical Dental Technology; proof that education is definitely the way forward.

It was on this amazing high that I travelled straight from the ceremony to another major event in my life: the Trailwalker 2007.

\section{A strong team}

A few months previously Dr Dan Shaffer, a dentist and (so called) friend of mine, casually asked me if I wanted to raise a team for a sponsored walk for charity, and foolishly I agreed. He and I work very well within the surgery as a strong team and we have built up a great friendship - one which was put to the test over the 27 hours of the Trailwalker.

Our team of four was to start at Petersfield and walk to Brighton - a total of 62 miles $(100 \mathrm{~km})$. We set off on Saturday morning at $8 \mathrm{am}$ and we walked ... and we walked ... and we walked ... until eventually at $11.30 \mathrm{am}$ on Sunday we finished!

When I say I have never done anything as hard as that I am not joking. We only had ten checkpoints along the route where we could get water and change socks if necessary but 


\section{focus on teambuilding:}

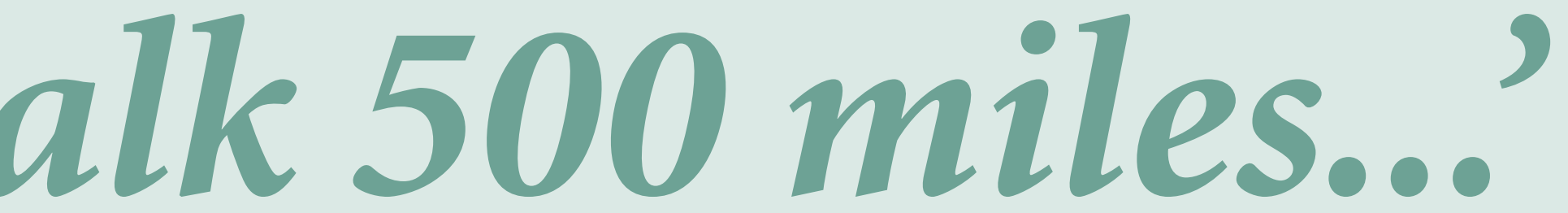

\section{'I thought getting a qualification as a CDT was hard, but this was endurance of the toughest!'}

otherwise it was 'best foot forward' and eat as we went. I thought getting a qualification as a CDT was hard, but this was endurance of the toughest!

\section{Vindaloo elevenses}

We laughed all the way round and hats off to the terrific support of the Gurkhas who were cheering us all on every step of the way. The Gurkhas also supplied us with an amazing curry at the end of the walk. I have never walked so far for a curry in my life and never eaten a curry, for that matter, at $11.30 \mathrm{am}$ on a Sunday - it was superb. I was cheered over the finishing line by the CDTA's cheerleading team - Phil Tucker and Diane Maisey known during office hours as Denture Design Studio in Hove.

This whole walk taught me one thing in particular, that team work is paramount to any success, and never volunteer to do anything unless you have researched it thoroughly on the Internet!

\section{A wonderful cause}

I would like to thank all those people who have donated to two wonderful causes: Oxfam and the Gurkha Welfare Trust (www.gwt.org. uk). Established in 1969, the Gurkha Welfare Trust aims to 'provide financial, medical and community aid to alleviate hardship and distress among Gurkha ex-servicemen and their dependants after they have returned to their homeland of Nepal'. For nearly 200 years the Gurkhas have helped fight Britain's wars and keep the peace, and many live in poor conditions in a harsh environment in Nepal.

In June I attended a CDTA meeting and raised over $\mathfrak{E} 300$ in donations, which together with other sponsorship brings my grand total to $£ 850$. The other team members raised equal amounts; altogether we have reached at least $£ 2,000$ and the figure is still growing. We are proud of the donation we have made to two good causes and would like to thank all those who supported us. If anyone wishes to make a further contribution please do not hesitate to contact me at paul.dentureclinic@virgin.net.

Has your surgery undertaken any unusual team-building activities? If you are interested in being featured in a Focus on, contact Kate Maynard on vitaleditorial@nature.com.

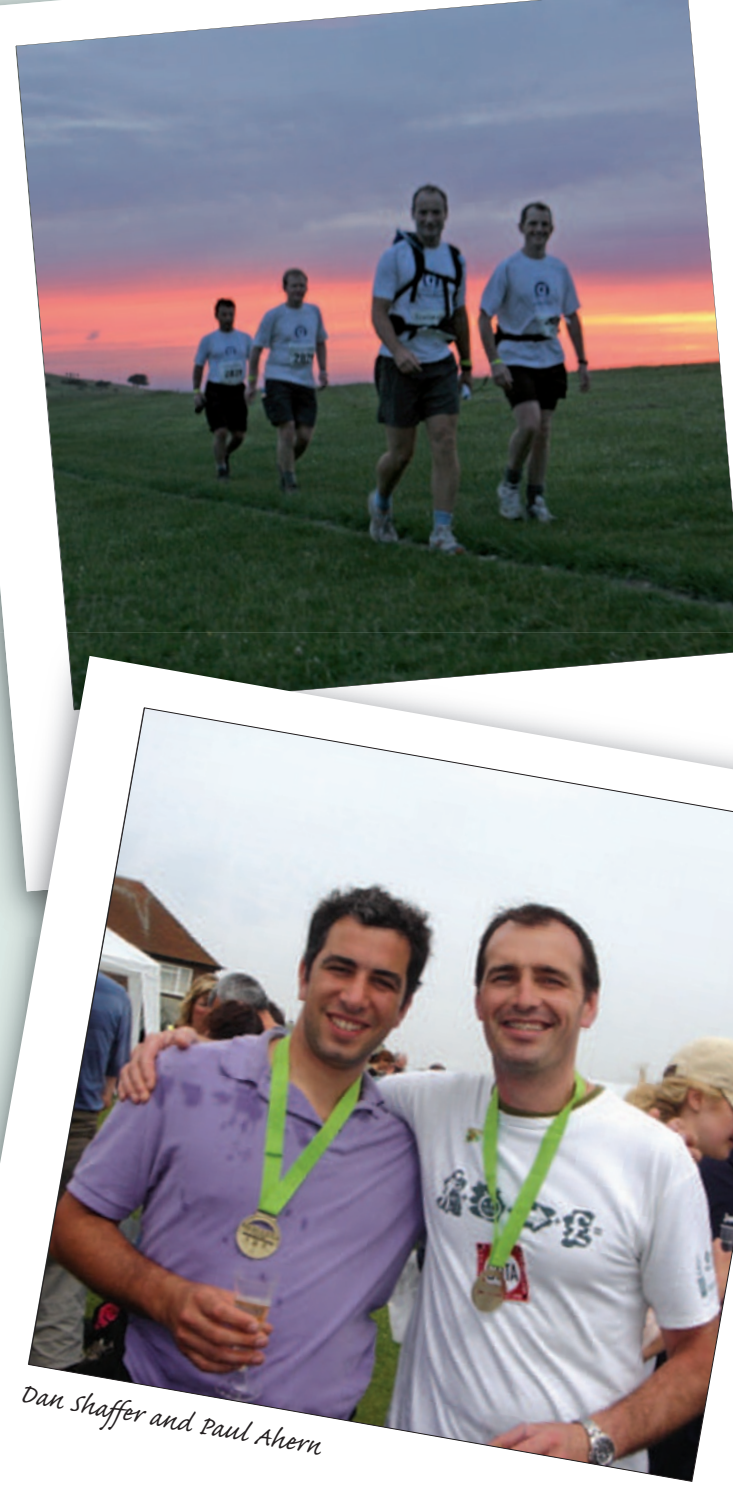

\section{Trailwalker}

Trailwalker UK is organised by Oxfam and the Gurkha Welfare Trust and is a $100 \mathrm{~km}$ trek for teams of four. The tough conditions test your stamina, endurance and navigation skills and are a great way to get fit and strengthen your team.

Four hundred teams took part in the event this year, even braving a dramatic thunderstorm. See www.oxfam.org.uk/get_involved/fundraise/trailwalker. 